\title{
Research and Application for Power-Grid Comprehensive Distribution Decision System
}

\author{
Qian $\mathrm{Gao}^{1^{*}}$, Shangyuan $\mathrm{Wu}^{2}$, Junyi Yang ${ }^{3}$, Kai Zhang ${ }^{4}$ and Chao $\mathrm{Xu}^{1}$ \\ ${ }^{1}$ State Grid Jiangsu Electric Power Co., Ltd., Nanjing, China \\ ${ }^{2}$ Beijing GuoDianTong Network Technology Co., Ltd., Beijing, China \\ ${ }^{3}$ Electric Power Economics Research Institute, State Grid Jiangsu Electric Power Co., Ltd., Nanjing, China \\ ${ }^{4}$ State Grid Yangzhou Jiangdu Power Supply Company, Yangzhou, China \\ ${ }^{*}$ Corresponding author
}

\begin{abstract}
High-efficiency power-grid planning is used to ensure the benefits and smooth operation of power-grid companies and industries. In order to solve the planning management business, such as the enterprise overall planning, power-grid planning and early planning, and its decision analysis issues, such as comprehensive planning, investment planning, production planning, etc. This paper proposes some statistical data models for power-grid planning decision and its applications. With some quantitative and data information analysis, the different decisions are designed for different plans and mathematical analysis methods are provided to decision makers. Taking the common decision analysis model as the carrier, a specific and applicable logic model is proposed with power-grid companies' business characteristics and decision-making requirements. The experimental results show that this power-grid planning method has the features of robust reregulation and universal adaptation with same types, which implied that the optimization constraints of this model are matching with the actual conditions and further ensuring the credibility and practicality of the power-grid planning.
\end{abstract}

Keywords-power-grid planning; statistical data model; decision-making requirements; robust reregulation; universal adaptation

\section{INTRODUCTION}

In order to improve the rationality and accuracy of comprehensive plan decision analysis, experts have carried out a lot of work. Bryson $\mathrm{N}$ explored possibilities that could result from the use of consensus relevant information embedded in the preference data that arise in group decision-making contexts and offer a set of similarity measures and consensus indicators for assessing the level of group consensus that could also be used by the group facilitator to develop strategies for increasing the level of group consensus [1]. Dong $\mathrm{Y}$ et al. presented two AHP consensus models under RGMM with some simulation experiments to show that the proposed two consensus models can improve the consensus indexes of judgement matrices to help AHP decision makers reach consensus [2]. Karaki S H et al. presented a methodology to solve the transmission congestion and tariff setting problems that may arise in a privatized or partially regulated power utility within the framework of a pool model to restructure the Electricite du Liban [3]. Ren $\mathrm{H}$ et al. developed an analytical model for estimating an economically efficient installation and operation pattern for the distributed energy system. As an illustrative example, a numerical study is conducted of feasible distributed energy system for a model area in Shanghai, while considering five scenarios with different technology combinations [4].

This paper proposes two statistical data models for power-grid planning decision and their applications. The remainder of this paper is structured as follows: Section 2 describes the goals and methods of decision analysis in power-grid planning management business; Section 3 introduces our proposed statistical data model for planning decision applications and the evaluation process of the proposed model; The evaluation method reported in this research is examined by a case study in Section 4; Conclusions about the proposed model are given in Section 5.

\section{DECISION ANALYSIS MODELS IN POWER-GRID PLANNING MANAGEMENT BUSINESS}

The efficient management of power resources and the formation of effective control and decision-making models for information delivery will make smart grid systems more economical, environmentally friendly and reliable. The power grid market has the characteristics of rapid changes in demand, and it is very necessary to carry out comprehensive processing of different information models to achieve analysis and cooperation of diversified systems. Such models are being used to support policy decisions on market design, merger analysis, market coupling and other regulatory tasks [5]. In our statistical data models, the main issue to be considered is to build an electricity sales allocation decision model. Another issue is to build an assisting decision-making model.

\section{A. Traditional Sales Allocation Decision Model}

Data-driven decision making is based on data analysis decisions rather than intuition. Machine learning models with optimal performance such as random forest, enhancements, support vector machines, and neural networks are simpler than Explain models (such as decision trees, naive Bayes, or decision-making) significantly improve predictive performance rules [6]. 
Gören H G presented a decision framework for sustainable supplier selection and order allocation problem [7]. In the field of retailers, a method of optimal inventory allocation with limited shelf space and two unreliable suppliers in an uncertain environment was proposed. The proposed concepts and analysis models provide allocation preferences between shelf space and warehouses in the context of deterministic and stochastic demand and develop management insights based on these models. For each case, closed-form solutions and heuristics are provided and the boundaries of the optimal solution are illustrated [8].

\section{B. Traditional Allocation Decision-making Assist Model}

Energy planning using multi-standard analysis has long attracted the attention of policy makers. Traditional single-standard decisions are usually designed to minimize costs and realize benefits. New methods need to better understand the intrinsic characteristics of the decision-making problem, promote the role of participants in the decision-making process, promote compromise and collective decision-making, and provide a good platform for understanding the perception of models and analysts in the real world [9]. In addition to energy planning, MCDM applications also include integrated manufacturing systems, technology investment assessment, water and agricultural management $[10,11,12]$. the optimal mathematical models for resource allocation [14] is presented for solving large-scale energy-allocation problems with partially observable states, utility functions and constrained action is introduced.

\section{STATISTICAL DATA MODEL FOR POWER-GRID PLANNING DECISION}

The planning of electricity sale allocation is dynamic, non-linear and uncertain which is difficult to form a unified sale allocation decision-making model. Traditional methods are mostly focused on the analysis and research of the integrated planning management operation mode of enterprises. We presented our quantitative sale allocation decision-making model to formulate the unified allocation strategies.

\section{A. Electricity Sales Optimal Allocation Decision Model}

The current overall goal of electricity sales is mainly human intervention. The goal of this paper is to construct a forecast model for electricity sales and further optimize the overall goals set by manpower. The power prediction model includes a regression model, a time series model expert system, etc. This paper selects a logistic regression model and a deep belief network model to predict the annual target value of electricity sales, and measures the minimum squared error, and obtains the sales model's optimization weight. Electricity optimal target value.

Logistic regression model [14] needs to determine the best regression coefficient $\mathrm{W}$ for the input $\mathrm{X}$, enter $\mathrm{Z}=W^{T} * X$ into the Sigmoid function:

$$
f(z)=\frac{1}{1+e^{-z}}
$$

The output is greater than 0.5 , belongs to class 1 . If less than 0 , belongs to class 0 . Logistic regression is "the best fit parameter for the Sigmoid function." The iterative update formula for $\mathrm{W}$ is:

$$
\mathrm{w}=w^{\prime}+\alpha * w^{T} * \text { error } .
$$

Where error is the output error when the weight is $\mathrm{W}$ :

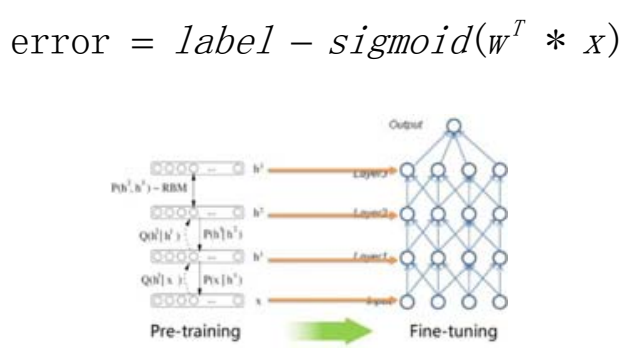

FIGURE I. THE STRUCTURE OF DEEP BELIEF NETWORK

The main idea of the deep belief network (shows in Fig,1) is to regard each hidden layer in the multi-layer perceptron as an implicit layer in the (three-layer) neural network that minimizes the difference between output and input. Learning + top-down supervision learning [15].

\section{B. Optimal Allocation Decision-making Assist Model}

The optimal decision-making assist model carries on the unified data interface with the data center and constructs the auxiliary decision-making system based on the overall goal allocation decision-making model. At the same time, it will allow decision-making data to be updated over time and make information delivery and decision analysis easier.

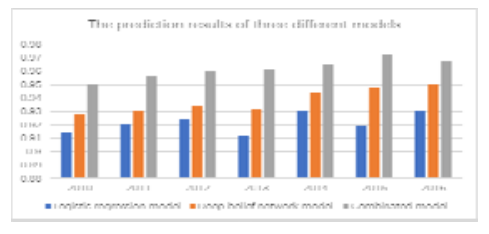

FIGURE II. THE PREDICTION OF THREE DIFFERENT MODELS IN LOCATION A.

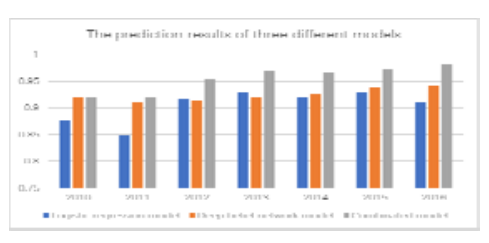

FIGURE III. THE PREDICTION RESULTS OF THREE DIFFERENT MODELS IN LOCATION B. 


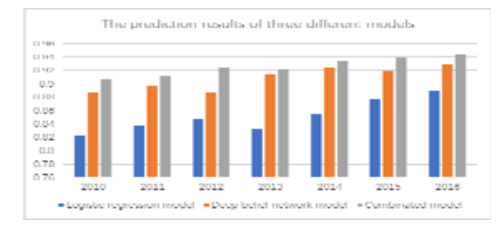

\section{FIGURE IV. THE PREDICTION OF THREE DIFFERENT MODELS IN} LOCATION C.

The results of three different models in location A are listed in Fig. 2 indicated that the best forecasting model has a maximum prediction accuracy of $97.23 \%$ and there is an average prediction accuracy of $94.18 \%$. The results of three different models in location B are listed in Fig.3 indicated that the best forecasting model has a maximum prediction accuracy of $98.14 \%$ and there is an average prediction accuracy of $95.50 \%$. The results of three different models in location $\mathrm{C}$ are listed in Fig.4 indicated that the best forecasting model has a maximum prediction accuracy of $94.47 \%$ and there is an average prediction accuracy of $92.61 \%$. It implied that the combined forecasting scheme can execute the decision-making requirements efficiency.

\section{Summary}

This paper proposes two statistical data models for power-grid planning decision and their applications. With some quantitative and data information analysis, the different decisions are designed for different plans and mathematical analysis methods are provided to decision makers. Taking the common decision analysis model as the carrier, a specific and applicable logic model is proposed with power-grid companies' business characteristics and decision-making requirements. The experimental results show that this power-grid planning method has the features of robust reregulation and universal adaptation with same types, which implied that the optimization constraints of this model are matching with the actual conditions and further ensuring the credibility and practicality of the power-grid planning.

\section{REFERENCES}

[1] Bryson N. Group decision-making and the analytic hierarchy process: Exploring the consensus-relevant information content[J]. Computers \& Operations Research, 1996, 23(1): 27-35.

[2] Dong Y, Zhang G, Hong W C, et al. Consensus models for AHP group decision making under row geometric mean prioritization method[J]. Decision Support Systems, 2010, 49(3): 281-289.

[3] Karaki S H, Chahine H T, Salim B A. Congestion management and pricing in the restructured power system of Lebanon[C]. Power Engineering Society Summer Meeting, 2002 IEEE. IEEE, 2002, 3: 1333-1338.

[4] Ren H, Zhou W, Nakagami K, et al. Feasibility assessment of introducing distributed energy resources in urban areas of China[J]. Applied Thermal Engineering, 2010, 30(16): 2584-2593.

[5] Neuhoff K, Barquin J, Boots M G, et al. Network-constrained Cournot models of liberalized electricity markets: the devil is in the details[J]. Energy Economics, 2005, 27(3): 495-525.

[6] Bohanec M, Borštnar M K, Robnik-Šikonja M. Explaining machine learning models in sales predictions[J]. Expert Systems with Applications, 2017, 71: 416-428.
[7] Gören H G. A decision framework for sustainable supplier selection and order allocation with lost sales[J]. Journal of Cleaner Production, 2018, 183: 1156-1169.

[8] Luo K, Bollapragada R, Kerbache L. Inventory allocation models for a two-stage, two-product, capacitated supplier and retailer problem with random demand[J]. International Journal of Production Economics, 2017, 187: 168-181.

[9] [Pohekar S D, Ramachandran M. Application of multi-criteria decision making to sustainable energy planning - a review[J]. Renewable and sustainable energy reviews, 2004, 8(4): 365-381.

[10] P. Putrus. Accounting for intangibles in integrated manufacturing-non-financial justification based on analytical hierarchy process. Information Strategy,1990, 6: 25-30.

[11] T.O. Boucher, E.L. McStravic. Multi-attribute evaluation within a present value framework and its relation to analytic hierarchy process[J]. The Engineering Economist, 1991, 37: 55-71.

[12] Ranganathan P, Nygard K E. Maximization of the Utility Function, Time-Dependent Energy Allocation, and Fuzzy-Logic Resource-Allocation Models[M]. Distributed Linear Programming Models in a Smart Grid. Springer, Cham, 2017: 109-124.

[13] Ranganathan P, Nygard K E. Maximization of the Utility Function, Time-Dependent Energy Allocation, and Fuzzy-Logic Resource-Allocation Models[M]. Distributed Linear Programming Models in a Smart Grid. Springer, Cham, 2017: 109-124.

[14] Alsharif A A A, Pradhan B. Urban sprawl analysis of Tripoli Metropolitan city (Libya) using remote sensing data and multivariate logistic regression model[J]. Journal of the Indian Society of Remote Sensing, 2014, 42(1): 149-163.

[15] http://slidesplayer.com/slide/11378370/. 